\title{
Universal Expression of Geological Data on the Perspective of Public Management
}

\author{
Xin Lian ${ }^{1}$ Lianrong Zhao ${ }^{2}$ \\ ${ }^{1}$ Xin Lian $;^{2}$ Lianrong Zhao (China University of Geosciences(Beijing), School of \\ Humanities and Economic Management, 100083)
}

\begin{abstract}
:
The geological data was used widely in the past; nowadays the way to express professional geological data can not meet the needs of social development. Thus universal expression of geological data is needed. From the perspective of public administration, this article analyzes the properties of geological data and provides universal expression according to the different types of users' needs.
\end{abstract}

Keywords: geological data; universal; public goods

\section{Introduction:}

As the result of geological work, geological data is widely used in geosciences, such as mineral resources exploration and development, national defense construction, infrastructure, urban construction, environmental protection, disaster prevention and mitigation and other economic construction and social development in all aspects. it is highly technical to present geological data. With the development of our society and economy, resource and environmental problems have become increasingly widespread concern social issues. With the increase of public focus on environment, the demand for geological data also increases. There is an urgent need for different types of geological data to understand issues they concern, which requires owners and managers of geological data be responsible for geological data. They must provide universal geological data for the people. This article tries to investigate how professional geological expressions transform into universal means of expression.

\section{The meaning and characteristics of geological data}

\subsection{The meaning of geological data}

According to the provisions of "Geological Data Management Regulations", geological data refers to the geological work in the form of the text, graphics, audio and video, and other forms of electromagnetic medium original geological data, the results of geological data and rock mineral core, various specimens, the light sheet, samples and other physical geological data.

Some scholars believe that geological data is the records and cognition of the geological phenomena or geologic body with different forms of text, graphics , audio and video, electromagnetic media , real [ rock ( ore ) heart, various specimens, the light sheet, the sample ], etc. which is formed in the course of geological work .For better generalization 
of geological data, this definition would be used in this article .

\subsection{Features of geological data}

- Geological data has several carriers. According to the definition of geological data, it falls into three types in accordance with its production stage: the results of geological data, original geological data, and physical geological data.

Main carriers of geological data include paper, polyester film, audio and video tapes , film ( tape ), disks, CDs , rock ( ore ) heart, specimens, samples, and other light sheet. Among these, the main carriers of results and original geological data are paper carriers ( including paper, film, etc. ), audio and video carriers ( including video tapes, audio tapes, microfiche, photographic film, etc. ), electronic media ( including floppy disk , CD-ROM , etc. ). Moreover, physical geology data carriers include rock and mineral core, specimens, samples, and other light sheet. Different types of texts, maps, data, and samples combine to make up the numerous and a wide variety of geological data.

- geological data has various ways of formation

Based on its definition, geological data consists of not only original geological data such as data and text which was directly obtained in the course of geological work, but also the results of geological data which was formed in post-processing. Because of the gradualism of understanding, the accuracy and the integrity of geological results would be limited by objective factor. Therefore, a lot of geological data were got on the basis of the previous studies and for further studies.

- Geological data has several of service objects.

When we view data about service status of geological collection agencies, it can be seen that the number of users, the number of units, the service times and the number of copies all showed an upward trend. For example, the number of users of the national geological archives has risen from 768 in 2001 to 12,408 in 2012 .Its Service sectors involve in mining, metallurgy, nonferrous metals, chemicals , agriculture, forestry , construction, machinery, etc. , which covering almost sectors of society . There are several types of the users, such as scientific research institution, universities, operating units, government departments, individuals and other types.

\section{The attributive analysis of geological data based on the theory of public goods}

According to the theory of public economics, social products are divided into public goods and private goods .In Samuelson's view, pure public goods or services is the product or service that everyone consumes such goods or services does not result in the kind of products or services of others reduced. And public goods or services have three characteristics such as the indivisibility of utility, non-excludability and non-rivalry, which are different from the private goods or services. The excludability and rivalry are basic characteristics of private goods. Quasi- public goods or "hybrid products" is between public goods and private goods, which refers to a limited non-excludability and non-rivalry public goods. Based on the theory of public goods, geological data will be divided into public geological data goods, nonpublic geological data goods and quasipublic geological data goods.

\subsection{Public geological data products}

Public geological data goods are a kind of geological data which have three 
characteristics such as the indivisibility of utility, non-excludability and non-rivalry. It mainly consists of the basic and nonfor-profit geological data that was invested by the state, such as the Compulsory public geological data, regional survey data and so on.

\subsection{Non- public geological data products}

Non- public geological data products refer to the kind of geological data that was funded by private or business. For excludability and rivalry, it can only be used by people who have the exploration and mining rights in the period of protection of geological data. However, it still needs to follow the summarization and submission of geological data because of the national ownership of geological data.

\section{3. quasi-public geological data products}

The property of quasi-public geological data goods, as it shows to us, is potential exclusiveness and it is crowded public products .Quasi-public geological data products is between public geological data products and non-public geological data products . It can not only be opened to be available to the general public, but also be auctioned and assigned to a specific department, enterprise or individual.

\section{4. universal expression and its principles}

The universality, is the property that one thing (especially the concepts, systems and laws, etc.) universally applied to similar objects or things. The universality of geological data means to make the geological data universally applied to the public. What is worth mentioning that the "public" here can be divided into different objects, so that expression of different objects is different.
The awareness of geological data runs the first in what the public demand, in other words, the public obtain meaningful impression of geological data through hearing and seeing. The second is understanding, it means to know what geological data is. Following is the application of geological data; geological data would be used in several aspects of social life in order to achieve their social value. Finally, geological data service need feedback, so that geological data managers to improve the geological data services. Universal expression of geological data is to make different types of the public aware, understand and use geological data better.

Universal expression of geological data should follow the following principles:

\section{1. the principle of fairness}

Universal expression of geological data is to provide better service to the public, so it must combine the principle of fairness when we choose the ways of expression .The principle of fairness here mainly refers to access and use data equality. The same type of users must have the same and fair way and conditions to obtain geological data, at the same time, different types of users obtain the same geological data in the same way.

\section{2. the principle of university}

The expression of geological data would be classified to accord with the use's characteristics and needs .With the increasing need for geological data ,the traditional window-type services cannot meet the needs any more .For example, a simple geological data does not meet needs for acquisition. We must take full account of the applicability of specific ways, what meet the demand characteristics, even the user's individual characteristics. 


\section{3. the Principle of pilot demonstration}

Select several service agencies to make experiments .To make secondary operation for geological data based on different types of users and provide to users .In the process, we need to know the satisfaction degree of the amount ,relevance and accuracy of geological data ,so that improve the service and give some reference for promoting the universal expression of geological data in the future.

\section{5. the way of universal expression of geological data}

The users of geological data can be divided into four types of government users ,non-profit users(such as scientific research institution, universities, etc.),for-profit users and public users .Geological data should be provided change from the traditional supply-driven to demand-driven. Therefore, we should provide universal geological data product according to the needs of different types of users.

\section{1. promotional products for the public}

The importance of the geological sciences to the social development is self-evident, which related to all aspects of human life. Therefore, the popularization of geological science requires the participation of the whole society, with government investments as the mainstay, the geological society, colleges, enterprises and the media act with united strength, translate geological data into promotional products that is easy to understand, so as to achieve a multiplier effect.

The geological data with the value of development and utilization should be published in time, by making full use of television, Internet and other modern means of propaganda. Through geological results conference and product promotion of geological products to promote the work of geological information publicity and popularization, so that so that the public can get geological data conveniently and efficiently.

\section{2. comprehensive products for government user}

The government's decision is in need of a reference to geological data, so the geological data what suit the needs of different department should be provided. Comprehensive products is obtained by comprehensive analysis of geological data of different majors, different methods and different period, and then to find out the inherent law. According to the special requirements of the production operation and the economic activities, the comprehensive or single geological data products can be compiled that was aimed at the important economic zone, national important metallogenic zone, construction area, major project of major geological disaster area, important geological problems areas. For example, a series of geological data can be comprehensive analyzed such as data of basic geology, mineral geology ,geological, geochemical, geological remote sensing, natural heavy concentrate, and then to summed up the regional metallogenic regularity, so as to metallogenic prediction

\subsection{Ordering products for for-profit users}

To make deep processing of products on the basis of the public goods above, so that to provide differentiated and diversified services and meet the needs of individual users. The users who have the intention of working in the field of mineral resources exploration can apply 
to geological collection agencies for advice of the implementation of mineral exploration in the relevant area. With knowing the demand information, the agency would collect data and then form a set of geological data of mineral exploration in the area .Service agencies may establish standards for ordering products for fee.

\subsection{Professional data for non-profit users}

Development of geological science is continuous, so there would be nothing new findings if without the basis of the past. Basic research should be carried out on the basis of predecessors' work, so obtaining new materials would be combined with the secondary development of the old data. It would provide detailed and accurate geological data products for non-profit users such as scientific research institutions, educational departments and so on. For example, the raw data and processed data of geomagnetic observation would only be used in the study of science by a particular scope of researchers.

\section{References:}

[1] Zhou Jinsheng, Ru Xianglan, "Evaluation of Social service of geologic data."[M]. Beijing. Geological Publishing House, 2012

[2] Chen Peizhang, "The geological events, National geological archives part. " [M]. Beijing: Geological Publishing House, 2012

[3] Joseph.E.Stiglitz, “Economics. [M]. Beijing: People's University Publication House, 1997

[4] $\mathrm{Ru}$ Xianglan, "the situation and problems of public service of geological data." Proc. Sixth National Geological Archives Symposium, Beijing: China land press, 2008

[5] Jiang Ruixue, "The legal framework of Geological data copyright protection." Proc. Theory Monthly, 2011, 9.

[6] Yao Huajun, “ Thinking about advancing geological data of public service." Proc. Geological bulletin, 2009 (Z1)

[7] http://www.mlr.gov.cn/zwgk/zytz/201 304/t20130418_1204958.htm 